\title{
Private Sector and Waste \\ Management in Delhi: A Political Economy Perspective
}

\author{
Ashish Chaturvedi, Rachna Arora and Manjeet Singh Saluja
}

\begin{abstract}
Due to their size and rapid growth, large cities in developing countries are increasingly challenged by burgeoning waste generation. Waste management, however, has traditionally provided employment opportunities to the many urban poor in the informal sector. These traditional models, working largely in parallel with state-led interventions, are under pressure because they fail to address the waste management crisis. This failure, coupled with the lack of capacities of local governments, has paved the way for formal private sector participation. We examine the case of Delhi where a complex interplay of competing approaches have accompanied efforts of urban local bodies, civil society and the private sector (informal and formal) at finding a sustainable working solution. Our analysis of the complex relationship within the private sector players, and between private and public actors, provides novel insights into potential contribution of public-private partnerships for effective waste management in developing countries.
\end{abstract}

\section{Introduction}

Due to an increase in both population and disposable income, waste generation has been rising at an unprecedented rate over the last two decades in developing countries. The associated challenges of open dumping and burning of waste are most pressing in large urban agglomerations with high density of population, unplanned urbanisation and weak physical infrastructure (Government of India 2009). Waste management, however, also creates economic opportunities for the urban poor seeking to make a living in the large cities of developing economies. Waste is managed by a range of actors in the informal sector. These actors are involved in the entire waste management value chain, from collection, segregation and transportation, to repair, reuse and recycling. Such involvement of the informal sector is driven by economic necessity. Waste management provides low entry-cost opportunities to the urban poor. The material value of waste is able to provide them with the financial resources to earn a living without making substantive investments. However, not all fractions of the waste stream have value that can be recovered without making investments.
Such fractions are not of interest to the informal sector and are usually littered, dumped and burnt in the open.

With rapid urbanisation, traditional models of waste management that relied on the informal sector are under pressure because they fail to solve the waste management crisis. Visible large quantities of waste and the increasing awareness of the citizenry has put an additional burden on local government who are responsible for the cleanliness of cities. But local government is illequipped to face these challenges largely due to lack of capacity which emanates from the limited know-how, limited access to finance and governance gaps in the management and functioning of the local bodies (Chaturvedi, Arora and Kilguss 2011). These limitations of the public sector have paved the way for private sector participation in waste management. The rationale for private sector engagement is straightforward. The private sector has access to and understanding of technology and is more cost-effective. Further, it is envisaged that the participation of the private sector can reduce the burden on urban local bodies (Dukhan, BourbonSeclet and Yannic 2012). 
The arguments in favour of private sector participation have, however, predominantly focused on large, formal waste management companies. As a result, formal waste

management companies have expanded business rapidly in the large cities of developing countries. The role of the informal sector as private actors who also support local governments in managing waste, although well documented, has not been acknowledged by local government to the same extent. The differential treatment meted out to actors in the private sector has led to an underestimation of the overall contribution of the private sector to waste management and has also created conflict that undermines the potential of both the informal and formal sector.

We examine the case of waste management in Delhi. The challenges associated are well known - waste is dumped in open areas and burnt on the streets which can lead to conflicts between large waste management companies as well as with the informal sector. The case of Delhi is interesting because of the complex interplay of competing approaches that have accompanied the efforts of the urban local bodies, citizen groups and civil society as well as the private sector (both informal and formal) at finding a sustainable working solution. At various points in time, and on occasions concurrently, the politics of waste management has been dominated by one or other approach.

This plurality of approaches and the dynamic nature of a complex landscape lends itself to a critical analysis of the political economy of waste management in Delhi. We focus our attention on the interaction between the public and private sector, both informal and formal, in this analysis. The core question is the following: in a complex and dynamic landscape, under which conditions does private sector partnership with the public sector lead to better outcomes as compared to business as usual? We answer this question by examining the alliances and conflicts within the private sector (between the informal and formal), as well as between the private and public sector (especially local governments) in the case of Delhi. We examine the role of the public sector in waste management and how it engages with multiple private sector actors. Also, an examination of the complex relationship within private sector players, and between the private and public actors, provides new insights into the potential contribution of these partnerships to effective waste management in developing countries.

In Section 2, three distinct approaches to waste management, with varying degrees of involvement of the private sector, are described. The section also examines the many private sector actors who are involved in waste management in urban agglomerations such as Delhi, the roles and interests of the various actors who drive these approaches and the emergence of a particular kind of private sector participation as the dominant mode of implementing waste management solutions. We then generalise the lessons from the Delhi experience to identify conditions under which private sector involvement can lead to better outcomes as compared to business as usual.

\section{Approaches to waste management}

Waste management is one of the most pressing problems of urban local bodies in developing economies. The resulting environment and health crisis combined with narratives of cities drowning in their waste has led to the search for solutions. The search for solutions has broadly taken two different approaches - decentralised and centralised - driven by different actors and interest groups (Chatri and Aziz 2012).

The decentralised approach focuses on distributed community-level initiatives. These solutions focus on enhanced community participation in waste management, emphasise the development of decentralised infrastructure such as local material recovery facilities and involvement of existing players in waste management, including the informal private sector. The aim is to reduce dependence on the local government, enhance citizen engagement and seek the support of the informal sector to provide waste management services. The main drivers behind this approach are civil society actors from non-governmental organisations (NGOs) and citizen groups as well as representative organisations of the informal sector. These organisations form alliances with like-minded officials within the local government as well as community organisations and elected representatives. Such initiatives also find support from small-scale private sector initiatives as well as social entrepreneurs who see a business opportunity in waste management. Although the aim is to reduce dependence on the local 
government, it must be noted that the development of decentralised infrastructure (through provision of land) as well as the participation of the informal sector (through processes of recognition and formalisation) is possible only through the cooperation of the local government.

The centralised approach, by contrast, although driven by the same starting point - the inability of local governments to deliver effective waste management services - proposes radically different solutions. The proponents of a centralised approach focus on the development of large infrastructure for composting, setting up of waste-to-energy plants and city-wide contracts with large formal waste management companies. The crisis of waste management is also an opportunity for the proponents of the centralised approach - the opportunity to make wealth out of waste and recover energy. The centralised approaches are driven to a large extent by national and local governments who lack capacity and are facing pressures to find quick solutions. They see private sector involvement in waste management as a cure-all. There is a shared interest and opportunity-based alliance between these local governments and large waste management companies who can obtain large value contracts for providing city-wide waste management services. The promise of a clean city, generating energy from waste and reducing the administrative and financial burden of the local government provides the necessary support for the alliance between the city government and the formal waste management companies. Civil society and citizen groups play a critical watchdog role in this approach but have limited active engagement in waste management. The widespread informal sector is seen as a competitor for the formal waste management agencies because it competes with the formal private sector actors for access to waste.

A combination of the two approaches described above could also be used as a potential solution. In these hybrid approaches, certain stages of waste management - usually collection, segregation and composting - are organised in a decentralised manner while recycling and recovery of materials (including energy) is organised centrally. However, the design and implementation of such models requires active engagement and innovation by the local government. In the absence of sufficient capacity in local government, such hybrid approaches usually tend to converge over time to the centralised model. This drift towards the centralised model is due to the transaction costs of managing conflicts between the private actors involved in different stages of waste management. The hybrid models, at least in theory, are able to overcome the conflict between the informal and formal sector, embedded in both the decentralised and centralised models. However, the critical challenge for implementing these models is to overcome the political economy barriers because the informal actors would like to push towards the decentralised model while the formal actors would lobby for the centralised solutions. The barriers emerge because both the informal and formal sector believe that the potential gains from collaboration would be less than if they were to manage waste independently. However, with a suitably designed public-private partnership (PPP) led by an active and capable local government, both parties could benefit if they collaborated.

It is clear from the previous discussion that in all three approaches, the local government has substantive influence. Although the involvement of the private sector is premised on relieving the burden of the local government, it is the local government that has significant influence on the choice of approach, the design of the chosen approach and the resulting role of the private actors from the informal and formal sectors.

\subsection{The many private sector actors in waste management}

All three approaches outlined above envisage a role for the private sector in waste management. However, the actors from the private sector in each approach are different. This point is critical to develop a nuanced understanding of private sector participation. Such an understanding would also allow for an analysis of private sector actors and identifying potential conflict and cooperation opportunities within the private sector rather than labelling the private sector as one homogenous entity. If one agrees that informal waste management actors are also part of the private sector, then private sector participation has always been at the heart of waste management in most urban areas in developing countries. The informal waste sector, especially vibrant in low- and middle-income 
countries, plays an important role in waste management (CWG-GIZ 2010; Scheinberg, Wilson and Rodic 2010). It recovers much larger amounts than the formal sector in both the centralised and decentralised approaches. These actors, despite their marginalised position and their simple equipment, often recover up to onethird of the waste in a self-financing way (Gunsilius et al. 2011). In spite of being informal, the actors in the sector are highly organised. The informal sector has a logic of its own based on economic efficiency and sharing of surplus through the entire value chain (Coad 2005).

There have been attempts in different parts of the developing world to forge partnerships between the informal sector and local government which look very similar to PPPs. However, the existing literature and policy discourses on PPPs in waste management predominantly focus on large-scale infrastructure and centralised contracts for waste management. The focus on large-scale infrastructure is driven by a host of factors that are highlighted in the Delhi experience outlined in the next section.

Another crucial group of private actors that are overlooked, especially in developing countries, are the product manufacturers whose products (and their packaging) lead to a substantial contribution to waste. Most developed countries in Europe, as well as Japan, have focused on extended producer responsibility to put the onus of waste arising out of products on the manufacturer. However, there is limited experience on similar initiatives in developing countries. Further, all the private sector actors (mostly informal micro-, small- and medium-sized enterprises) who are involved in reducing waste generation through repair and reuse are also not a part of most discussions on waste management (Kaushal, Varghese and Chabukdhara 2012). It must be noted that reduction of waste generation ranks higher in the waste management hierarchy - an ordering of waste management options in terms of their environmental impacts - as compared to recycling.

By not acknowledging or wilfully ignoring the entire array of private sector actors, private sector contribution supporting waste management is either underestimated or not fully utilised by the public sector. We believe that a nuanced understanding of the many private sector actors in waste management is a particularly crucial determinant of the failure or success of PPPs.

\section{Waste management and the private sector - the Delhi experience}

Delhi has been at the centre of the race to transform waste management through PPPs and the use of technological solutions. As per the Delhi Master Plan (Delhi Development Authority 2010), 'Vision 2021 is to make Delhi a global metropolis and a world-class city, where all the people would be engaged in productive work with a better quality of life, living in a sustainable environment'. The short-, medium- and longterm goals as specified in the Solid Waste Action Plan outlined in the Delhi Master Plan mention the development of new sanitary landfills, treatment technologies such as refuse derived fuel (RDF), closure and restoration of existing landfills and PPPs for waste treatment. The focus of the Action Plan is on the development of largescale infrastructure projects aimed at solving the waste management problem through partnership with large formal private sector companies. The Master Plan mentions the role of informal sector recyclers in waste management and the setting up of markets (bazaars) for recyclables. However, the Solid Waste Action Plan of the Master Plan omits this discussion completely while presenting details of the financing of infrastructure and resource allocation for activities listed under the Action Plan.

The focus on a centralised approach poses a major threat to the livelihoods of the waste workers because they must increasingly compete with private firms for ownership and control over recyclables at multiple stages (Schindler, Demaria and Pandit 2012). Both the informal and formal sectors are interested in the high calorific value of the recyclable fraction of the waste. The informal sector is interested in the recyclable fractions because it can recover enough value to sustain the livelihoods of the various informal sector actors without making substantial investments. The formal sector is interested in the recyclables because it would like to maximise the returns on the infrastructure investments in the centralised model, including the waste-to-energy infrastructure. The rivalries between these systems are related to the right of ownership of waste that not only displaces the informal sector 


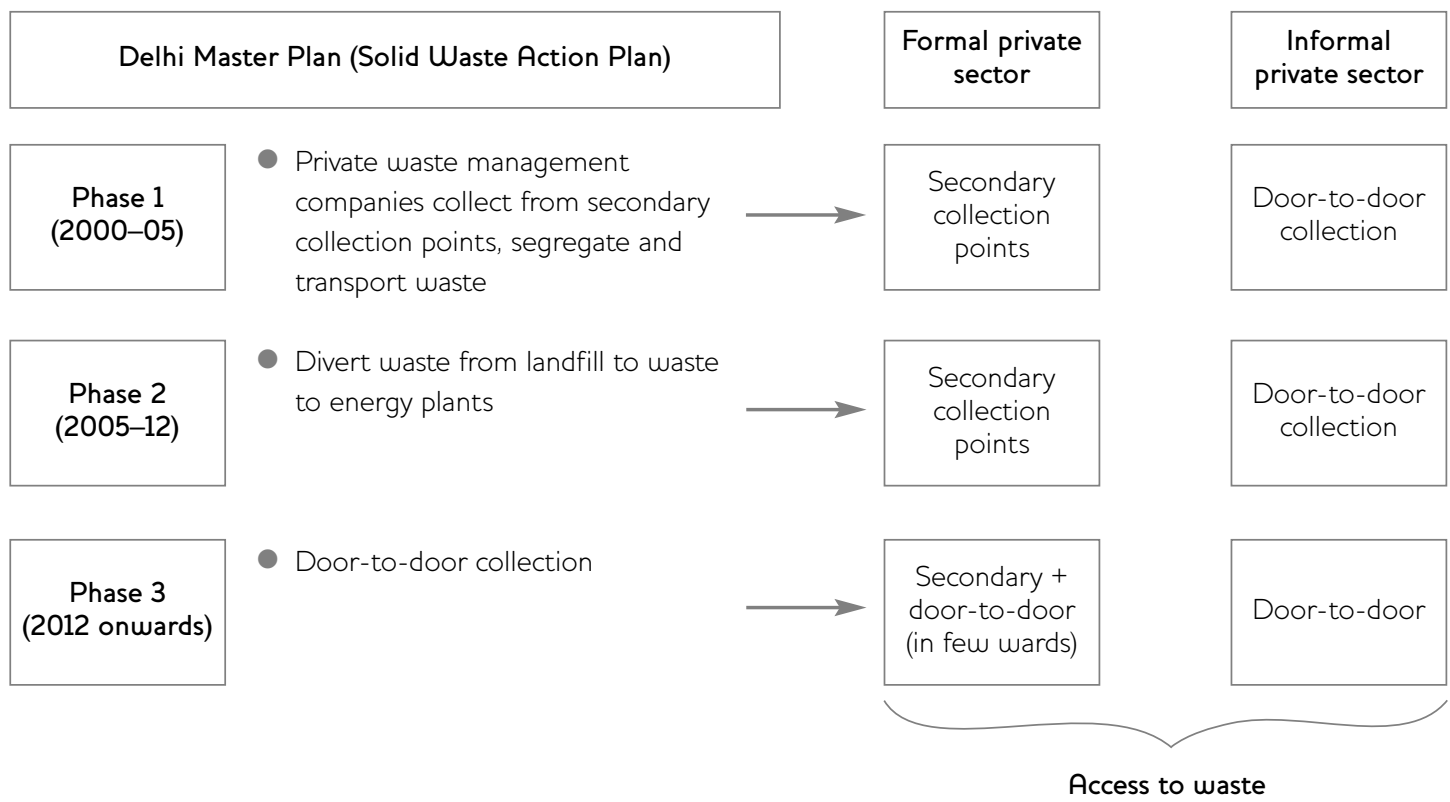

Source Authors' own based on Schindler et al. (2012).

but also reduces the recovery and recycling efficiency (Gidwani and Reddy 2011; Gavé 2012). The reduction in recovery and recycling is due to the fact that the large-scale companies would rather incinerate the mixed waste (and recover energy) than invest additional financial resources in material recovery.

The advent of PPPs as a mode for encouraging private sector participation in waste

management in Delhi began nearly a decade ago. Schindler et al. (2012) identify three phases in this process (see Figure 1). In the first phase, the municipalities of Delhi involved companies to collect, segregate and transport waste. However, the collection was restricted to secondary collection points which allowed the space for informal actors to collect waste door to door. Formal private sector players were involved in bidding for the waste as well as for the fee they would receive from the state for its collection (Chaturvedi and Gidwani 2011). These contracts led to both social and environmental challenges. The social challenges emanated from the issue of who owned the waste. The private waste management companies got into conflicts with both door-to-door collectors of waste as well as informal actors picking up recyclables from the secondary collection points. The environment challenge emanated from the contesting of the basic principles of the $3 \mathrm{Rs}$ (reduce, reuse and recycle) by designing contracts that favoured 'more waste to landfill'. By signing quantitybased contracts with the formal private entities, private companies were incentivised to transport ever more quantities of waste for landfilling. The focus of the second phase was to divert waste from Delhi's landfills to waste-to-energy plants. In December 2006, the government proposed a waste-to-energy plant that would not only help the city manage its waste but also generate energy in the process. Further, the plant was registered with the United Nations Framework Convention on Climate Change (UNFCCG) to obtain carbon credits for reducing greenhouse gas emissions. The focus on waste-to-energy that requires high calorific value waste to achieve the desired results would have implications for further reducing access of the informal sector to recyclables. The operation of the plant had multiple problems related to the quality of waste, the quality of emission monitoring and local opposition from the residents living in the vicinity of the plant. The third phase, initiated in 2012, plans to extend the reach of private firms to households by granting them the right to 
door-to-door collection. As part of the strategy, the waste management system is progressively being handed over to large waste management companies thereby reducing access to waste by the informal sector.

\section{Actors and interests}

Waste, much like its composition, is a complex challenge. The starting point for understanding the complexity and associated challenges is to recognise the multiplicity of actors, interests, technologies and approaches. The interplay between the actors and their interests and how they play out under different approaches is critical for any intervention. In our understanding, the dominant approach is determined to a large extent by the dominance of a particular coalition of interests at any particular juncture. For instance, over the last six years, since the launch of a national urban renewal mission, a state-led initiative has made attempts to transform the landscape of Indian cities. There is a shared interest and opportunity-based alliance between the big waste management companies and the state to transform the urban landscape. As a result, the dominant approach has leaned towards a centralised model. This does not imply that the space for the other approaches, supported by those left out of this alliance, has been usurped, but it has nonetheless shrunk. On occasions these alternative approaches - supported by environmental NGOs, informal sector activists or even certain sections of the state - express themselves in the various policy processes and platforms contesting the dominant approach.

The Delhi experience is a stark example of how things can fall apart in the process of redesigning market systems through state intervention. To our understanding, the major challenge in Delhi was the uneasy relationship between the large numbers of informal recyclers and the local government responsible for waste management (Agarwal et al. 2002). Driven by documents such as the Vision 2021 (Delhi Development Authority 2010) and narratives of urgency, the government embarked on a systematic plan for launching PPPs in the waste management system without resolving this uneasy relationship. The attempt was to shift the burden onto the formal private sector with the underlying assumption that the private sector would succeed where the local government has failed. In this process, the local government, with the convening power for dialogue and conflict resolution, created spaces for and exacerbated the conflict between the informal and formal sectors.

However, by embarking on PPPs without acknowledging the role of the informal private sector as a market actor, the local government has not been able to eliminate the informal sector. The informal sector exists and continues to be involved in a significant manner in handling waste in Delhi. The reason is the following informal waste value chains are based on the material value of the recyclables in the waste stream and do not depend on any support outside the market system in which they operate. The unplanned efforts at facilitating private sector participation through PPPs had the unintended consequence of splitting the private sector into two conflicting parties - the informal and formal. The two have been involved in conflict in both the discursive and material arenas.

On the one hand, large waste management companies were behind the discourse related to the energy potential of waste that could contribute to resolving the energy crisis in India. This discourse also implied that waste should be diverted from the informal sector actors to the waste-to-energy plants. However, there was limited evidence to support these claims, especially given the low calorific value of the urban waste streams in India and multiple failed attempts at establishing waste-to-energy plants. At the same time, there was widespread discrediting of the contribution of the informal sector. Such discrediting involved, amongst others, efforts at branding the informal sector as drug addicts, thieves and relics of a pre-modern society who should not be allowed space in a modern world-class city. At the same time, the rising quantities of waste and the associated fractions which could not be handled by the informal sector have meant that waste has increasingly become a visible problem. With increasing awareness about the environmental and health implications of open dumping and burning of waste, the limitations of the informal sector have also been exposed. The large formal sector players claim to overcome these limitations, including avoidance of crude processes of uncontrolled waste management processes as well as the use of child labour and illegal migrants. 
On the other hand, the informal sector represented through unions such as the All India Kabari Mazdoor Mahasangh, Safai Sena and NGOs such as Chintan - has been involved in promoting a rights-based approach for the involvement of informal sector actors (Safai Sena 2009). They were involved in generating evidence and advocating the economic efficiency of the informal sector and the environmental benefits due to more efficient recycling, including the reduction of greenhouse gas (GHG) emissions. At the same time, they were involved with the support of international alliances such as the Global Alliance for Incinerator Alternatives (GAIA), in raising the challenges associated with the waste-to-energy plants. These advocacy efforts against incinerators were strengthened through the persistent failure of waste-to-energy plants and their inability to comply with local standards for emission control. Also, the failures provided the space for environmental NGOs such as Toxics Link and the Centre for Science and Environment to highlight the potential environmental damages that came about due to the failure of the waste management infrastructure.

\section{Generalising lessons from the Delhi experience on PPP design}

First, as mentioned, a thorough understanding of the political economy of a market system is essential to design effective private sector engagement including PPPs. In order to achieve such an understanding and encourage participation of the relevant stakeholders, actors with convening powers such as the local government play a pivotal role. By choosing to open up or close down policy spaces, the local government has a critical role in promoting discussion and deliberation about private sector participation. The Delhi experience suggests that the local government did not open up the debate on PPPs in waste management for the relevant stakeholders. This led to the creation of competitive alliances and appropriation of spaces provided by the failures or weaknesses of the adversarial alliance. The local government could have opened up the debate through what Forsyth (2005) describes as deliberative PPPs.

Deliberative PPPs are 'defined as partnerships that maximise public debate about the purpose and inclusivity of collaboration between state, civil, and market actors, as well as achieve the economic purposes of collaboration'. However, the opening up of debate by the actors with convening powers is only possible if it doesn't conflict with their own interests and priorities at that particular juncture.

Related to the above is a broader understanding of both the private sector in relation to waste management, as well as waste management itself. The dominant discourse on private sector participation focuses on large waste management companies involved in waste management using technological solutions. The focus is largely on managing the waste generated with little attention on waste minimisation. As a result, myriad actors in the informal sector, involved in the repair and reuse industry who divert large quantities of potential waste from reaching recycling infrastructure, including landfills, are largely outside the ambit of discussions on waste management. By failing to support this industry and investing in developing the waste management infrastructure, local government promotes a throw-away society. Further, the role of manufacturers whose products (and their packaging) contribute to waste have not been included explicitly in most discussions on private sector participation for waste management. Such limited focus is in contrast to Europe and Japan where the product manufacturers have been integrated into waste management through policy instruments such as extended producer responsibility (EPR). EPR imposes the financial (and physical) responsibility for establishing a take-back system and waste recycling arising from products and packaging onto the manufacturers. This assignment of responsibilities onto the manufacturers has the impact of reducing the financial and physical burden on the municipalities of certain fractions of the waste stream. The Delhi experience is symptomatic of a focus on end-of-pipe solutions for waste management. There is limited attention to incentivising reduction, reuse and repair through participation of a wide network of private actors that will have an impact on the quantities of waste generated.

Second, with a clear understanding of the diversity of interests within the private sector, PPPs could be designed to encourage collaboration between the informal and formal private sector actors (Scheinberg et al. 2010; Gupta 2012). Such collaboration resulting in the hybrid model described would, however, be forged through the convening power and 
leadership of the party commissioning the PPP such as the local government or other state actors. The reliance on informal and formal actors to develop collaborative partnerships without effective mediation and moderation results in transitory (and potentially exploitative) relationships. These relationships would work most effectively in cases where the two sectors can rely on the expertise and experience of the other in distinct parts of the value chain (Chaturvedi et al. 2011). In waste management such a division of the value chain is possible. With the informal sector's expertise in collection, segregation and dismantling and the formal sector's expertise in advanced technological solutions for scientific disposal and recovery of materials (and energy), cooperative models could be evolved.

As a result, the governance and management capacities of the party commissioning a PPP are a prerequisite for its success (Le Courtois 2012; Coad 2005). PPPs based on transferring the burden on the public onto the private sector are likely to fail. Most PPPs are designed as projects that require skills in contract development and management as well as project life cycle management. If public provision of the services has failed because of the lack of these skills within the commissioning public sector department, this failure is likely to continue even with a PPP. In the worst cases, it could lead to substantial losses of public funds because the private sector is much more equipped and experienced in dealing with legal loopholes in PPP contracts.

Third, related to the second point, the contract between the public and the private party in waste management is another critical aspect for the effective implementation and success of a PPP. The Delhi experience suggests that weightbased contracts lead to perverse incentives for the private contractor (bringing more waste to the landfill provides higher revenues) and exacerbates the conflict between the informal and formal waste management sector. This is an obvious case of oversight and reflects a lack of understanding of the processes related to waste management. However, effective contracts would need to reflect an adequate understanding of the issue on which the PPP is being negotiated. Also, contracts would need to take into account the potential risks and different scenarios which could emerge once the contract is signed. Such nuanced and sophisticated contracting can only be developed and managed by a commissioning party with sufficient knowledge and skills.

Finally, the role of international cooperation by bilateral and multilateral agencies can be particularly effective if designed and delivered well, in building capacities for PPP development and implementation. Most of the support for PPPs in waste management has been provided to isolated projects that focus on effective implementation of the PPP in a particular context. However, a much more effective strategy would be to design meta-PPPs that build local capacities by engaging both public and private sector actors. The capacities of the public sector could be built, with the support of the private sector, on issues such as contract development and project management. At the same time, the capacities of the private sector could be built, with the support of the public sector, on stakeholder engagement and policy processes.

\section{Conclusion}

Over the last decade, there has been a rapid increase in private sector participation, especially PPPs, in waste management in developing countries. The impacts of these interventions have been mixed. We have examined the case of Delhi that launched PPPs in waste management and has been actively engaging with large formal private sector players in efforts to improve solid waste management. We find that a narrow focus on large private sector players and limited understanding of private sector participation has led to the formation of shared interest and opportunity-based adversarial alliances and conflict. Such conflict has the potential to thwart any effective implementation of public-private partnerships initiated by local government. We suggest that opening up spaces for dialogue and debate, acknowledging the diversity of private sector actors (and interests) and broadening waste management discourses are critical for effective private sector participation in waste management.

Our analysis is based on a single case and can be generalised only across certain dimensions.

However, in order to identify patterns of alliances and contingent factors essential for developing an understanding of sustainable waste management approaches, strands of future research on waste management must address the gap in research 
about the alliances, or coalitions of interests, that are behind successful and unsuccessful attempts at PPPs. Such an understanding can be developed through comparative political economy analysis of successful (and unsuccessful) PPPs in waste

\section{Note}

1 We would like to acknowledge Robin Murray who used this phrase describing private actors in waste management recently in a private correspondence.

\section{References}

Agarwal, R.; Gupta, S.K.; Sarkar, P. and Ayushman (2002) Recycling Responsibility. Traditional Systems and New Challenges of Urban Solid Waste in India, Srishti Report, 2 June, http://toxicslink.org/docs/munispalwaste/ Recycling\%20Responsibility_mail.pdf (accessed 20 September 2014)

Cavé, J. (2012) 'Urban Solid Waste in Southern Countries: From a Blurred Object to Common Pool Resources', World ISWA Congress 2012, September 2012, Florence, Italy

Chatri, A.K. and Aziz, A. (2012) 'Public Private Participations in Solid Waste Management, Potential and Strategies', Athena Infonomics India Pvt Ltd, www.gov.uk/government/ uploads/system/uploads/attachment_data/file/ 186990/ReportPPPMunicipalSolidWaste Management270812.pdf (accessed 1 October 2014)

Chaturvedi, B. and Gidwani, V. (2011) 'The Right to Waste: Informal Sector Recyclers and Struggles for Social Justice in Post-reform Urban India', in W. Ahmed, K. Amitabh Kundu and R. Peet (eds), India's New Economic Policy: A Critical Analysis, London: Routledge Chaturvedi, A.; Arora, R. and Kilguss, U. (2011) 'E-Waste Recycling in India - Bridging the Formal-Informal Divide', in S. Mukherjee and D. Chakraborty (eds), Environmental Scenario in India: Successes and Predicaments, London: Routledge

Coad, A. (2005) 'Private Sector Involvement in Waste Management - Avoiding Problems and Building on Successes', Collaborative Working Group on Solid Waste Management in Low- and Middle-Income Countries, www.skat.ch/ publications/prarticle.2005-09-29.7288084326/ skatpublication.2005-11-11.0299659281/file (accessed 25 September 2014)

CWG-GIZ (2010) 'The Economics of the Informal Sector in Solid Waste Management', management. This research will generate evidence and create an enhanced understanding of coalitions of interests, across historical and institutional settings, which could drive or block attempts at sustainable solid waste management.
Collaborative Working Group on Solid Waste Management in Low- and Middle-Income Countries, www.cwgnet.net/prarticle.2010-1104.5920431459/prarticle.2011-03-30.0366272418 (accessed 20 October 2014)

Delhi Development Authority (2010) Master Plan for Delhi - 2021, New Delhi: Delhi

Development Authority

Dukhan, A.; Bourbon-Seclet, C. and Yannic, N. (2012) 'Linking Public and Private Action for Sustainable Waste Management', Private Sector and Development 15: 9-11

Forsyth, T. (2005) 'Building Deliberative Public-Private Partnerships for Waste Management in Asia', Geoforum 36.4: 429-39 Gidwani, V. and Reddy, R.N. (2011) 'The Afterlives of "Waste": Notes from India for a Minor History of Capitalist Surplus', Antipode 43.5: $1625-58$

Government of India (2009) The Solid Waste Management Sector in India, position paper, November, Department of Economic Affairs, Ministry of Finance, www.pppinindia.com/pdf/ ppp_position_paper_solid_waste_mgmt_112k 9.pdf (accessed 26 October 2014)

Gunsilius, E.; Spies, S.; García-Cortés, S.; Medina, M.; Dias, S.; Scheinberg, A.; Sabry, W.; Abdel-Hady, N.; Florisbela dos Santos, A.L. and Ruiz, S. (2011) Recovering Resources, Creating Opportunities - Integrating the Informal Sector into Solid Waste Management, Eschborn: Deutsche Gesellschaft für International Zusammenarbeit (GIZ)

Gupta, S.K. (2012) 'Integrating the Informal Sector for Improved Waste Management', Private Sector and Development, www.proparco.fr/ jahia/webdav/site/proparco/shared/

PORTAILS/Secteur_prive_developpement/ PDF/SPD15/SPD15_Sanjay_k_Gupta_uk.pdf (accessed 3 October 2014)

Kaushal, R.K.; Varghese, G.K. and

Chabukdhara, M. (2012) 'Municipal Solid 
Waste Management in India - Current State and Future Challenges: A Review',

International Journal of Engineering Science and Technology 4.4: 1473-89, www.ijest.info/docs/IJEST12-04-04-196.pdf (accessed 20 October 2014)

Le Courtois, A. (2012) 'Municipal Solid Waste: Turning a Problem into Resource', Private Sector and Development 15: 2-4

Safai Sena (2009) Cooling Agents: An Examination of the Role of the Informal Recycling Sector in
Mitigating Climate Change, Report, New Delhi: Advocacy Project, Chintan Environmental Research and Action Group, Safai Sena

Scheinberg, A.; Wilson, D.C. and Rodic, L. (2010) Solid Waste Management in the World's Cities, London: UN-Habitat, Earthscan

Schindler, S.; Demaria, F. and Pandit, S.B. (2012) 'Delhi's Waste Conflict', Economic and Political Weekly XLVII.42: 18-21 